\title{
Is Laparoscopic Liver Resection Safe and Comparable to Open Liver Resection for Hepatocellular Carcinoma?
}

\author{
Kevin Tri Nguyen, MD, PhD and David A. Geller, MD \\ UPMC Liver Cancer Center, Starzl Transplant Institute, Department of Surgery, University of Pittsburgh, Pittsburgh, PA
}

The field of surgery has evolved to increasingly incorporate minimally invasive approaches. Although the use of laparoscopy gained rapid and widespread acceptance for the treatment of benign diseases such as biliary and gastroesophageal reflux diseases, its utility in the treatment of cancer has been more cautious due to initial concerns of compromising oncologic principles and fears of port-site recurrence. For colon cancer, a 10-year randomized clinical trial was conducted to compare laparoscopically assisted versus open colectomy, showing that the rates of recurrence were similar between the two groups and suggesting that the laparoscopic approach was an acceptable alternative to open resection for colon cancer. ${ }^{1}$ Liver surgery itself has evolved significantly with a better understanding of liver anatomical segments, enhanced imaging, improvements in anesthesia techniques including maintenance of low central pressures during liver mobilization and resection to prevent bleeding, and improved postoperative care and nursing. Minimally invasive liver resection is the next challenge; however, it has been slower to gain widespread acceptance, especially for cancer, due to concerns of compromising oncologic principles, uncontrollable hemorrhage, bile leakage, and air embolism. ${ }^{2}$ In addition, there has been lack of adequate training of liver surgeons in both open liver surgery and minimally invasive techniques.

No randomized controlled trial has compared laparoscopic liver resection with the traditional open liver resection; however, numerous case series have shown that it is safe and feasible in experienced hands. ${ }^{3-13}$ Initially performed with nonanatomical wedge resections of peripheral liver lesions, laparoscopic liver resections are being performed with anatomical liver resections (left

(C) Society of Surgical Oncology 2009

Published Online: 2 May 2009

D. A. Geller, MD

e-mail: gellerda@upmc.edu lateral sectionectomy, left hepatectomy, right hepatectomy, extended left hepatectomy, extended right hepatectomy, and central hepatectomy). Almost 3,000 laparoscopic liver resections have been reported in the world literature, $50 \%$ of which were for malignancies, with a cumulative morbidity and mortality of $10.5 \%$ and $0.3 \%$, respectively. ${ }^{14}$

In the absence of a randomized controlled clinical trial, a case-controlled analysis provides another option to compare laparoscopic liver resection with open liver resection. The article by Sarpel et al., entitled "Outcome for patients treated with laparoscopic versus open resection of hepatocellular carcinoma: a case-matched analysis" sought to compare the outcomes of laparoscopic versus open liver resection for hepatocellular carcinoma (HCC), with specific emphasis on surgical margin status and survival. ${ }^{15}$ To this end, the authors performed a casematched analysis between 20 laparoscopic cases and 56 matched open controls based on cirrhosis and tumor size within $10 \%$. The laparoscopic procedure employed four or five trocars, with a hand port as needed. Vascular inflow control with the Pringle maneuver was not performed and parenchymal transection utilized a combination of harmonic scalpel and vascular staplers. Open hepatectomies were performed with a curved subcostal or chevron incision with superior extension. The Pringle maneuver was routinely performed and parenchymal transection was by a modified crush-clamp technique using a closed Metzenbaum scissors to divide the liver tissue and clips to ligate the exposed structures. Outcome measures that were analyzed included operative time, intraoperative transfusion rate, margin status (positive if $\leq 3 \mathrm{~mm}$ ), length of hospital stay, 30-day readmission rate, tumor recurrence, and survival.

The study period for the laparoscopic group was 20042007 and for the open hepatectomy group was 1997-2007. There were no significant differences reported between the two groups based on age, gender, baseline cirrhosis, and 
tumor size; however, there was a trend towards older patients undergoing laparoscopic surgery compared with the open group (64 years versus 58 years, $p=0.054$ ). Results of univariate and multivariate analyses showed that there was no significant difference in the operative time, rates of intraoperative transfusion, rates of positive margins or 30-day readmission rates between the laparoscopic and open resection groups. However, the percentage of patients with length of stay $\geq 6$ days was significantly higher in patients undergoing open hepatectomy [odds ratio 0.09, $95 \%$ confidence interval (CI) 0.03-0.32]. After median follow-up of 24 months for the laparoscopic group and 18 months for the open group, the authors found no significant difference in overall survival (hazard ratio 0.11 , 95\% CI 0.01-1.01) and disease-free survival (hazard ratio $0.76,95 \% \mathrm{CI}=0.30-1.96$ ) between the two groups. For the laparoscopic group, the projected 5-year overall survival was $>95 \%$ and recurrence at 5 years was $50 \%$; however, this may be a generous projection, given that the median follow-up for the laparoscopic group was 2 years and at least $70 \%$ of patients in the sample should be deceased to make sure the analysis, using censored data, is correct.

This case-matched analysis by Sarpel et al. provides evidence that laparoscopic liver resection for $\mathrm{HCC}$ is oncologically comparable to open liver resection for $\mathrm{HCC}$, in regards to surgical margin, overall survival, and diseasefree survival. The improved length of hospital stay in patients undergoing laparoscopic liver resection suggest that the benchmark criteria for discharge (ambulation, tolerating oral intake, pain controlled with oral pain medication) was reached in the laparoscopic group sooner than in the open group. These results are comparable to those reported in the literature on laparoscopic liver resection for HCC. Cherqui et al. in 2006 provided midterm results showing the safety, feasibility, and oncologic efficiency of laparoscopic liver resection of 27 patients with HCC in a background of chronic liver disease. ${ }^{12}$ Surgical margins averaged $11 \mathrm{~mm}$ and overall 3-year overall and diseasefree survivals were $93 \%$ and $64 \%$, respectively. Simillis et al. in 2007 conducted a meta-analysis of eight studies, totaling 409 resections, comparing 165 laparoscopic liver resections (LLR) versus 244 open liver resections (OLR) for benign and malignant lesions. ${ }^{16}$ From an oncological standpoint, there was no differences in tumor-free margin status, overall survival (5 year, 61\% LLR versus $62 \%$ OLR), and disease-free survival (5 year, 31\% LLR versus $29 \%$ OLR) between laparoscopic and open liver resection for cancer. ${ }^{16,17}$ In addition, the laparoscopic resection group sustained less blood loss, achieved earlier oral intake, and were discharged to home sooner than the open resection group.
In summary, this study by Drs. Schwartz and Labow's group offers further support to the premise that laparoscopic hepatectomy for HCC provides short-term benefits to patients without compromising long-term oncologic outcomes, thus providing a safe and comparable alternative to open liver resections for HCC in experienced hands. Surgeons should be trained in performing both open liver resections and advanced minimally invasive techniques. Until a large randomized, controlled clinical trial comparing laparoscopic with open liver resection for cancer is initiated, similar to that performed for colon cancer, critics of the minimally invasive approach will remain. However, such a trial comparing laparoscopic with open hepatic resection is likely to be challenging, as patients may resist being randomized to a more invasive procedure. In addition, such a trial would require a large sample size to detect small differences in complication rates. Alternatively, as minimally invasive surgery is increasingly adopted by liver surgeons, a registry to track all laparoscopic liver resections should be considered to track all perioperative outcomes and help detect infrequent, but significant, occurrences of complications that may be too small to be detected by a clinical trial.

\section{REFERENCES}

1. Nelson H. A comparison of laparoscopically assisted and open colectomy for colon cancer. The Clinical Outcomes of Surgical Therapy Study Group. N Engl J Med. 2004;350(20):2050-9.

2. Nguyen KT, Gamblin TC, Geller DA. Laparoscopic liver resection for cancer. Future Oncol. 2008;4(5):661-70.

3. Buell JF, Thomas MT, Rudich S, et al. Experience with more than 500 minimally invasive hepatic procedures. Ann Surg. 2008;248(3):475-86.

4. Koffron AJ, Auffenberg G, Kung R, Abecassis M. Evaluation of 300 minimally invasive liver resections at a single institution: less is more. Ann Surg. 2007;246(3):385-92; (discussion 392-4).

5. Koffron AJ, Geller DA, Gamblin TC, Abecassis M. Laparoscopic liver surgery: Shifting the management of liver tumors. Hepatology. 2006;44(6):1694-700.

6. Cho JY, Han HS, Yoon YS, Shin SH. Experiences of laparoscopic liver resection including lesions in the posterosuperior segments of the liver. Surg Endosc. 2008.

7. Chen HY, Juan CC, Ker CG. Laparoscopic liver surgery for patients with hepatocellular carcinoma. Ann Surg Oncol. 2008;15(3):800-6.

8. Topal B, Fieuws S, Aerts R, et al. Laparoscopic versus open liver resection of hepatic neoplasms: comparative analysis of shortterm results. Surg Endosc. 2008.

9. Descottes B, Glineur D, Lachachi F, et al. Laparoscopic liver resection of benign liver tumors. Surg Endosc. 2003;17(1):23-30.

10. O'Rourke N, Shaw I, Nathanson L, et al. Laparoscopic resection of hepatic colorectal metastases. HPB (Oxford). 2004;6(4):230-5.

11. Kaneko H, Otsuka Y, Tsuchiya M, et al. Application of devices for safe laparoscopic hepatectomy. HPB (Oxford). 2008; 10(4):219-24.

12. Cherqui D, Laurent A, Tayar C, et al. Laparoscopic liver resection for peripheral hepatocellular carcinoma in patients with 
chronic liver disease: midterm results and perspectives. Ann Surg. 2006;243(4):499-506.

13. Gigot JF, Glineur D, Santiago Azagra J, et al. Laparoscopic liver resection for malignant liver tumors: preliminary results of a multicenter European study. Ann Surg. 2002;236(1):90-7.

14. Nguyen KT, Gamblin TC, Geller DA. World review of laparoscopic liver resection - 2,804 patients. Ann Surg, (in press).

15. Sarpel U, Hefti M, Wisnievsky J, et al. Outcome for patients treated with laparoscopic versus open resection of hepatocellular carcinoma: a case-matched analysis. Ann Surg Oncol. 2009.
16. Simillis C, Constantinides VA, Tekkis PP, et al. Laparoscopic versus open hepatic resections for benign and malignant neoplasms-a meta-analysis. Surgery. 2007;141(2):203-11.

17. Kaneko H, Takagi S, Otsuka Y, et al. Laparoscopic liver resection of hepatocellular carcinoma. Am J Surg. 2005;189(2): $190-4$. 